\title{
O AVANÇO DO ESTADO CONTRATANTE NO DIREITO DO URBANISMO: ESTUDO COMPARATIVO SOBRE OS CONTRATOS URBANÍSTICOS EM PORTUGAL E NO BRASIL
}

\author{
THE RISE OF THE CONTRACTING STATE IN URBAN PLANNING: COMPARATIVE STUDY OF \\ URBAN CONTRACTS IN PORTUGAL AND BRAZIL
}

Jorge André Carvalho Barreira Alves Correia*

\begin{abstract}
"O contrato é particularmente adequado às exigências contemporâneas de exercício do poder: a autoridade não é mais aceite por si mesma, a obediência ao direito é uma escolha racional que se baseia na livre discussão, «a decisão transforma-se num vasto processo de negociação»".
\end{abstract}

Laurent Richer, Droit des contrats administratifs, Paris, 2010, p. 49.

\begin{abstract}
Resumo:
O presente estudo tem por objeto a análise do atual processo de expansão do contrato urbanístico na atividade da Administração Pública. Assiste-se a um momento histórico de consolidação de uma administração por contrato, de crescimento do government by contract e de uma retórica do consenso. No campo urbanístico esse fenómeno tem tradução no recurso crescente a contratos para planeamento e contratos de execução de planos urbanísticos. No presente estudo interessa-nos destacar a relevância da teoria do contrato administrativo na compreensão das diferentes tipologias de contratos urbanísticos. Não obstante as evidentes vantagens associadas à escolha do contrato urbanístico, também são identificados alguns riscos associados à contratação. $\mathrm{O}$ estudo apresenta caráter comparativo.
\end{abstract}

Palavras-chave: Planeamento urbanístico. Contrato urbanístico. Estado Contratante. Contratos de planeamento. Estudo comparativo.

\begin{abstract}
:
This study aims the analysis of the current rising of the use of urban contracts in the activity of Public Administration. We are witnessing a historic moment of an administration by contract, the growth of government by contract and the rhetoric of consensus. In urban planning, this phenomenon translates into the growing use of planning agreements and urban planning contracts. In this study we intend to highlight the relevance of the administrative contract doctrine in understanding the different types of urban contracts. Despite the advantages related with the use of urban contracts, some risks linked with contracting were also identified. The present study is a comparative study.
\end{abstract}

\footnotetext{
* Professor da Faculdade de Direito da Universidade de Coimbra e Membro do Conselho Superior da Magistratura (Conselho Nacional de Justiça).
} 
Keywords: Urban planning. Urban contract. Contracting State. Planning agreements. Comparative study.

\section{Introdução}

O presente texto corresponde, nas suas linhas essenciais, à comunicação oral apresentada no dia 4 de setembro de 2019, na Faculdade de Direito da Universidade de São Paulo, no âmbito das $1 .^{\text {as }}$ Jornadas Luso-Brasileiras de Direito do Urbanismo. Na presente circunstância, em que temos a honra de colaborar novamente com a Faculdade de Direito da Universidade de São Paulo, transcrevemos, com singelas modificações, a nossa intervenção nas referidas Jornadas, mantendo, no essencial, a abordagem dos mesmos conteúdos. Assim sendo, propomo-nos fornecer ao leitor as grandes linhas da contratação urbanística em Portugal, sem abdicar das exigências comparativas que predicam um estudo desta natureza, designadamente esclarecendo as afinidades e as diferenças face ao ordenamento jurídico brasileiro.

Centraremos a nossa atenção na expansão do consenso na ação administrativa, em especial nos problemas da amplitude e limites do recurso ao contrato público como modus agendi da Administração Urbanística, o que - digamo-lo com clareza - representa um fenómeno próprio do nosso tempo, tanto em Portugal como no Brasil. Neste sentido, abordaremos as principais categorias de contratos urbanísticos, enquadrando-as na teoria geral do contrato administrativo, e aludindo ao problema do regime jurídico específico destes contratos, bem como à necessidade de acautelar a realização de valores fundamentais de direito público. Interessa-nos, num último momento, lançar a síntese comparativa, ou seja, lançar a pauta que enuncia as semelhanças e diferenças entre os termos a comparar, sem esquecer os fatores extrajurídicos que as determinam.

\section{A comparação dos direitos administrativos português e brasileiro}

A comparação jurídica começa por oferecer como valioso contributo o conhecimento do próprio direito público nacional, o que permite situar devidamente a ordem nacional entre os diferentes sistemas jurídicos. No fundo, a nenhum jurista português ou brasileiro é possível entender cabalmente o direito público em que é versado sem tomar consciência daquilo que, nos seus traços essenciais, o distingue dos demais. Mas o conhecimento da lei, da jurisprudência e da doutrina exteriores à ordem jurídica nacional é também muito útil aos cultores do direito administrativo, já que permite o 
alargamento dos estudos legislativos, bem como uma avaliação crítica das soluções normativas - elementos indispensáveis à boa política legislativa. ${ }^{1}$

O tema da contratação urbanística não se coloca nos mesmos termos em Portugal e no Brasil, sendo evidente a necessidade de realizar uma comparação por contraste, em geral, em matéria de organização político-administrativa do Estado e, em especial, em matéria de direito municipal. Como é sabido, Portugal é um Estado Unitário (art. 6. ${ }^{\circ}$ da CRP), com uma só Constituição e um sistema central de órgãos de soberania. Ao mesmo tempo, a CRP prevê expressamente a autonomia político-administrativa dos Açores da Madeira, como regiões autónomas, bem como a descentralização administrativa nas autarquias locais (municípios e freguesias). Isso permite qualificar o Estado português como um Estado Unitário descentralizado com autonomia regional. $\mathrm{O}$ que aproxima as regiões autónomas das unidades federativas é a existência de autonomia legislativa (ambas têm assembleia legislativa própria) e de autonomia governativa (ambas têm governo próprio). Contudo, há dois requisitos essenciais de um Estado federal, que um Estado unitário não preenche, por mais descentralizado que seja. Primeiro, num Estado federal, as entidades federadas gozam de autonomia constitucional, aprovando a sua própria constituição sem interferência do Estado, com respeito somente da constituição federal: não é o que sucede em Portugal, pois os estatutos político-institucionais das regiões autónomas são aprovados pelo Parlamento nacional, como leis orgânicas do Estado [art. 161. $\left.{ }^{\circ}, b\right)$, da CRP]. Segundo, num Estado federal, o parlamento federal é necessariamente bicameral, sendo a segunda câmara destinada à representação exclusiva das entidades federadas, que assim participam, enquanto tais, na função legislativa, na aprovação do orçamento do Estado federal e na reforma constitucional. Pelo contrário, em Portugal, não existe uma câmara de representação territorial das regiões autónomas no Parlamento, que habilite a sua participação no exercício do poder político nacional ou nas revisões da CRP.

O conceito de autarquias locais é exclusivo do direito constitucional português, não tendo paralelo noutros ordenamentos jurídicos. Trata-se de unidades territoriais de descentralização infraestadual e infrarregional, com autoadministração e autogoverno: à luz do art. 236. ${ }^{\circ}$ da CRP, são autarquias locais os municípios, as freguesias e as regiões administrativas (estas últimas nunca foram instituídas). Por sua vez, o termo autarquia não toma o mesmo significado no direito brasileiro, designando entidades da administração pública indireta, com autonomia administrativa e financeira, que podem ser federais, estaduais, distritais e municipais (autarquias institucionais).

No que diz respeito aos municípios, há pontos em comum e de distanciamento. O que aproxima ambos os sistemas é o facto de os municípios surgirem como sujeitos

Para uma visão de conjunto sobre a Comparação dos Direitos Constitucional e Administrativo português e brasileiro, cfr. a recente obra: Correia (2019, p. 15 et seq.). 
autónomos do poder central, com autoadministração e autogoverno. Todavia, em Portugal, os municípios não têm autonomia estatutária, já que o seu estatuto é uma lei da República, uniforme para todo o território nacional; pelo contrário, no Brasil, o município foi formalmente incluído na estrutura da Federação, enquanto parte ou componente daquela, e investido de outras dimensões de autonomia que vão muito além da autoadministração e do autogoverno, tais como a auto-organização, mediante a elaboração de lei orgânica própria, e a autolegislação, traduzida no poder de elaboração de leis municipais sobre áreas que são reservadas à sua competência exclusiva e suplementar. Neste capítulo, o direito brasileiro levou bem mais longe o princípio da autonomia municipal.

Já no Brasil, a CFB não deixa dúvidas sobre a caraterização da República como Estado Federal (arts. 1. ${ }^{\circ}$ e $18 .^{\circ}$ ), que compreende a União, os Estados, o Distrito Federal e os Municípios, todos autónomos nos termos da Constituição. Deste modo, a organização do poder político pressupõe quatro níveis de poder. O Brasil é um Estado Federal, mas, a meu ver, deve ser qualificado como Estado Federal atípico: essa atipicidade explica-se, desde logo, porque a CF visou reconfigurar aquele Estado como uma "federação de Municípios e de Estados". Assim, os Municípios são componentes da federação, mas não partilham das caraterísticas mínimas para constituírem unidades federativas.

Sendo o urbanismo uma questão essencialmente municipal, também é preciso levar em conta que, no plano orgânico e funcional, registam-se diferenças assinaláveis entre os direitos brasileiro e português. Primeiro, porque os municípios portugueses não dispõem de competência legislativa, nem estatutária. Segundo, porque o executivo municipal português designa-se Câmara Municipal, sendo o Presidente da Câmara o homólogo do Prefeito. Terceiro, porque os Vereadores são no direito português os titulares do poder executivo na Câmara Municipal, sendo uma espécie de "ministros executivos". Quarto, em Portugal, é a Assembleia Municipal o órgão deliberativo (e a Câmara Municipal o órgão colegial executivo). Por último, registam-se várias diferenças ao nível dos sistemas de governo municipal e da legislação de planeamento urbanístico.

Finalmente, quero chamar à atenção para o facto de se registarem outras diferenças no campo do direito administrativo geral: a primeira de ordem processual; e a segunda de ordem sistemática. Primeiro, em Portugal, observa-se a existência de uma jurisdição administrativa autónoma da jurisdição comum - jurisdição administrativa composta por tribunais administrativos com competência para o controlo da legalidade dos atos da administração pública. Ao contrário do Brasil que, desde 1891, adota o sistema de unidade de jurisdição, Portugal adota um sistema de dualidade de jurisdições, isto é, uma jurisdição administrativa e fiscal autónoma da jurisdição comum. Portanto, um modelo de contencioso administrativo francês, mas integralmente jurisdicionalizado, isto 
é, com tribunais administrativos obrigatórios nos termos da CRP, e com a originalidade de existir um conselho superior próprio da jurisdição administrativa e fiscal, o CSTAF.

Segundo, regista-se uma maior recetividade, em Portugal, à codificação do direito administrativo geral. Quanto à identidade, o direito administrativo português assume-se como uma ordem jurídica própria, mas tributária de influências externas, que confirmam um direito administrativo situado entre os direitos francês e alemão. Já o direito administrativo brasileiro combina na sua origem o direito francês, e no seu desenvolvimento elementos da common law, ${ }^{2}$ sem prejuízo de contributos pontuais dos direitos italiano e alemão em leis administrativas estruturantes.

\section{O fenómeno da contratação urbanística e a expansão da Administração por contrato}

Os primeiros anos do século XXI denotaram uma tendência de evolução dos sistemas administrativos ocidentais para a introdução do consenso e da concertação na atividade urbanística. ${ }^{3}$ Em rigor, essa tendência de evolução, embora seja apenas uma das faces de um fenómeno bem mais extenso, criou condições favoráveis para o alargamento da aplicação do contrato nas relações jurídico-públicas. A base ideológica do Estado Regulador, assente na premissa da redução da intervenção pública na economia, aumentou a dimensão do Estado Contratante e, sem surpresa, o contrato viu-se transformado num instrumento prioritário para a compra de bens e serviços indispensáveis à função administrativa (contracting out). Também neste contexto se assistiu à entrega da gestão de serviços públicos e de obras públicas a particulares, bem como ao aumento progressivo das concessões e das parcerias público-privadas. $\mathrm{O}$ aumento da dimensão do Estado Contratante e a expansão de uma administração pública por contrato, que encontram repercussão em praticamente todas as esferas de intervenção administrativa, traduzem uma cooperação mais ou menos sistemática entre atores públicos e privados no desenvolvimento das finalidades de serviço público.

Numa época em que se vive uma "euforia contratualizadora" no direito administrativo e uma profunda crença nos bons resultados da contribuição privada para a realização de fins públicos, a doutrina tem vindo a empregar diversos adjetivos e expressões metafóricas que permitem retratar e descrever, de forma pitoresca, o avanço do

\footnotetext{
Cfr. Marques Neto (2015, p. 74).

Sobre a contratação urbanística em Portugal, cfr. Correia (2009), (recensão de Martin Bassols Coma, na Revista de Derecho Urbanistico y Medio Ambiente, n. ${ }^{\circ} 275$, Año XLVI, jul./ago. 2012, p. 216-217); Correia (2012, p. 27-41; 2018, p. 91-112); Correia (2008, p. 469-483); Alexandra Leitão (2006, p. 9-32) e Fernanda Paula Oliveira e Dulce Lopes (2003, p. 43-80).

No ordenamento jurídico brasileiro, cfr. Guilherme Dias Reisdorfer (2014); Renata Schirato (2019, p. 249 et seq.); Thiago Riccio (2015); Gabriel Mundim (2014); Karlin Olbertz (2011); Mariana Senna Sant'Anna (2007) e Olavo Barboza (2018, p. 364-391).
} 
Estado Contratante: florescimento da "«paixão pelo contrato»"; 4 alargamento da "«onda contratual»",5 "preferência legal pela utilização do contrato administrativo"; 6 processo de "contratualização das políticas públicas"; 7 sistema de "contratos em cascata"; 8 modelo de "pilotagem através do contrato"; $;$ e "outsourcing de funções de soberania". ${ }^{10}$

Todas estas reflexões (europeias e norte-americanas) têm subjacente o facto de o moderno Estado Administrativo se ter convertido num "Contracting State", isto é, num Estado que interiorizou a "cultura do contrato" como um instrumento ao serviço da realização dos seus fins institucionais. ${ }^{11}$ Ora, esse paradigma (government by contract) é especialmente visível no direito do urbanismo, onde o contrato vem adquirindo extraordinária relevância, desde logo associado à abertura e estímulo da participação administrativa. Com o "despertar da participação administrativa", ${ }^{12}$ um pouco por toda a Europa avultam leis urbanísticas que reconhecem aos atores privados amplos direitos de participação, através de diferentes formas, na elaboração, alteração, revisão, execução e avaliação dos planos urbanísticos. O grau de intensidade ou de profundidade da participação dos atores privados no procedimento de formação dos planos e no âmbito da sua execução conduziu a uma redefinição do seu papel na prossecução de interesses públicos urbanísticos, o que abriu caminho, nas sugestivas palavras de Paolo Urbani (2000, p. 74), a um modelo de "codeterminação público-privada do ordenamento urbanístico".

Isto trouxe como consequência, na generalidade dos Estados-Membros europeus, iniciativas legislativas de regulamentação dos contratos urbanísticos. Fruto da expansão das regulamentações dirigidas aos contratos da administração pública, não surpreende que a contratação urbanística seja, hoje, um domínio regulado e objeto de controlo judicial pelas instâncias europeias, em especial pelo Tribunal de Justiça da União. ${ }^{13} \mathrm{O}$ relevo notoriamente crescente deste tipo de contratação, nos planos jurídico, mas também financeiro e económico, justificam a atenção particular da doutrina europeia. ${ }^{14}$

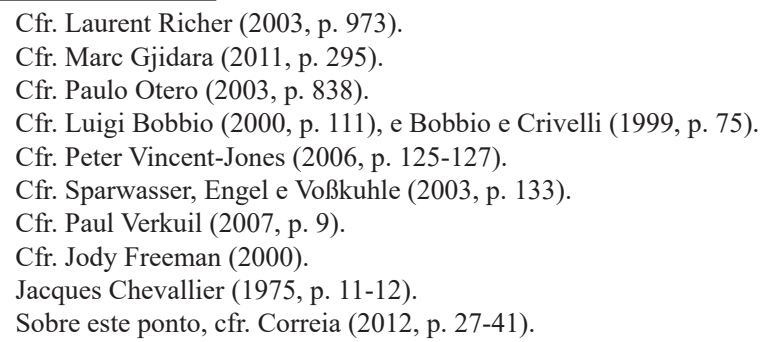

Para análise da contratação urbanística na generalidade dos ordenamentos jurídicos europeus, cfr., no ordenamento jurídico alemão, Volker Schlette (2000, p. 36-42); Elke Gurlit (p. 784-831); Eva Koch (2012, p. 250-273); Lenz e Würtenberger (2011, p. 37-138); Hans D. Jarass (Hs.) (2010, p. 1-12); Hans Büchner e Karlheinz Schlotterbeck (2008, p. 301-316); Michael Krautzberger (2007, p. 407-414), “§ 12”, Battis, Krautzberger e Löhr (Hrsg.) (2007, p. 280-291); Michael Krautzberger (2006, p. 1-4); Hans J. Birk (2002, p. 41-78); Ulrike Bick (2001, p. 154-161); W. Brohm (2000, p. 321-325); E. Schmidt-Assmann e Walter Krebs 
4. Funções e vantagens associadas à escolha do contrato urbanístico

Antes de passarmos à análise das figuras e regimes contratuais, sempre deveremos perguntar: o que leva a administração urbanística a utilizar a figura do contrato em detrimento de uma atuação unilateral? Dispondo a Administração de poderes de autoridade no campo do urbanismo para impor o direito aplicável à situação concreta, haverá vantagem em obter o consenso com os particulares? Num domínio onde existe até poder expropriativo para executar o plano, porque é que ela recorre ao contrato?

Pois bem, é que, apesar de todos os seus poderes de império: (1) a Administração não é proprietária de todos os bens e imóveis sobre os quais incidem a programação e a planificação; (2) a Administração não possui recursos financeiros ilimitados, antes escassos (é impossível lançar sempre mão da expropriação e de meios coativos); (3) a Administração necessita da colaboração dos privados para a execução dos planos, de tal forma que a execução dos planos pressupõe parcerias com os particulares; (4) logo, neste campo, não faz sentido que a Administração imponha autoritariamente tudo aquilo que pode obter consensualmente; (5) a grande vantagem do consenso é envolver o destinatário na implementação da própria decisão administrativa; (6) assim, reduz-se a litigiosidade e a conflitualidade permanentes; (7) mas também se alcançam melhores resultados que de outro modo não se alcançariam (não basta apenas cumprir formalmente a lei, sendo fundamental obter resultados ao nível da concretização do plano e ao nível da gestão urbanística - é o paradigma da «Administração de Resultados»; (8) Finalmente, importa não esquecer que mesmo quando a Administração utiliza o contrato administrativo, ela nunca perde os seus poderes de autoridade (são irrenunciáveis e inalienáveis) e, do mesmo modo, nunca perde o poder de atualizar o interesse público, já que tanto pode modificar como resolver unilateralmente o contrato administrativo.

Para o ente público, o recurso ao contrato confere a possibilidade de encontrar boas soluções urbanísticas para a cidade, recorrendo-se ao consenso quando há interseção entre o interesse público e o interesse privado. Para os promotores privados, a utilização do contrato cria maior previsibilidade e estabilidade: numa palavra, cria um

(1988). No ordenamento juridico francês, cfr. François Barloy (2006, p. 47-62); H. Jacquot e F. Priet (2006, p. 451-455); Pierre-Laurent Frier (2005, p. 13-15) e Nicolas Portier (2003, p. 986-989). No ordenamento jurídico italiano, cfr. Nicola Centofanti (2007, p. 3-27); Borella (1998, p. 419-447); Dino Borri (2007, p. 1721); Maria Mazza (2005, p. 9-35); Marco Magri (2004, p. 539-587); Ferdinando Parente (2007, p. 181-196); Giorgio Cugurra (2005, p. 144-155); Paolo Urbani (2000); Stefano Civitarese (1999, p. 132-141; 1997); Mario Nigro (1995, p. 33-66) e Candian e Gambaro (1992, p. 3-64). No ordenamento jurídico espanhol, cfr. Sendín García (2008, p. 11-39); Ochoa Gómez (2006, p. 15-55); Cano Murcia (2006, p. 28-60); Vicente Díaz (2003, p. 49-67); Arredondo Gutiérrez (2003, p. 1-80); Bustillo Bolado e Cuerno Llata (2001, p. 2589); Huergo Lora (1998, p. 27-32); Jerónimo A. Sierra (1996, p. 11-23). Cfr., ainda, os estudos e relatórios internacionais em Tanquerel, Morand-Deviller e Correia (2014). 
quadro de confiança que permite orientar o setor privado na decisão de realizar (ou de não realizar) investimentos em projetos urbanísticos. Tudo isto joga a favor do contrato urbanístico (städtebauliche Verträge, convenios urbanisticos, convenzioni urbanistiche, conventions d'aménagement ou planning agreements). ${ }^{15}$

Em síntese, o contrato é um instrumento que permite conciliar interesses públicos e privados; induz um quadro de confiança ou de compromisso entre os setores público e privado; e permite a captação de investimento privado ao nível da gestão urbanística.

5. $\mathrm{O}$ enquadramento dos contratos urbanísticos na teoria geral do contrato administrativo

Não existe um tipo de contrato urbanístico, mas vários tipos de contratos urbanísticos - a contratação urbanística é ampla e reveste natureza multifacetada ou pluriforme. O Direito do Urbanismo é um domínio particularmente rico de manifestações contratuais, em particular de diferentes tipos de contratos administrativos. Tanto o sistema português, como o sistema brasileiro reconhecem o contrato administrativo como figura autónoma, dotada de um regime jurídico próprio, distinto do regime dos contratos de direito privado da Administração (cfr. a Parte III do Código dos Contratos Públicos; e o Cap. III da Lei n. ${ }^{\circ} 8.666$, de 21/06/1993). ${ }^{16}$

Sucede, porém, que o ordenamento jurídico português foi mais longe do que o congénere brasileiro na consagração legal de dois modelos de contrato administrativo. Vale a pena lembrar que, em rigor, o contrato administrativo é uma instituição jurídica franco-alemã. Historicamente, a dogmática do contrat administratif foi recebida em Portugal e no Brasil. Contudo, para além do modelo francês de contrato administrativo (contrat administratif), a ordem jurídica portuguesa recebeu, desde meados da década de 90 do século passado, o modelo alemão de contrato administrativo (öffentlichrechtlicher Vertrag), consagrando-o no Código do Procedimento Administrativo (arts. 57. ${ }^{\circ}$ e $127 .{ }^{\circ}$ ) e estabelecendo o seu regime no Código dos Contratos Públicos (arts. 336. ${ }^{\circ}$ e $337 .^{\circ}$ ).

Assim, no plano da celebração de contratos administrativos entre a administração e os particulares, distinguem-se os contratos administrativos de colaboração (seguem o modelo francês) dos contratos administrativos sobre o exercício de poderes públicos (seguem o modelo alemão). Nos contratos administrativos de

15 Sobre as funções e vantagens associadas à escolha do contrato, cfr. o Capítulo II da Parte II (Título II) da Tese de Doutoramento. (CORREIA, 2017, p. 555 et seq.).

16 Sobre o contrato administrativo em Portugal e no Brasil, cfr. Pedro Costa Gonçalves (2015, p. 427 et seq.); e Fernando Dias Menezes de Almeida (2012, p. 12 et seq.). 
colaboração incluem-se, desde logo, os contratos de compras públicas de produtos e serviços: eis o que sucede com os contratos de empreitadas de obras públicas, de locação de bens móveis, de aquisição de bens móveis e de aquisição de serviços, disciplinados na legislação portuguesa e na legislação brasileira. Em causa estão contratos mediante os quais a administração adquire aos operadores económicos os produtos e serviços de que carece para desempenhar as suas missões. O contraente público fica investido na titularidade de "poderes exorbitantes", com vista a garantir a execução do contrato em nome do interesse público, que lhe conferem uma posição de supremacia jurídica sobre o seu contratante. A esta mesma categoria reconduzem-se os contratos de concessão, que associam, em regra por um prazo longo, um contraente público e um contraente privado, assumindo este último a responsabilidade de, em seu nome, conceber, executar ou gerir uma obra pública (concessão de obras públicas), de gerir uma atividade de serviço público (concessão de serviços públicos), ou de explorar um bem do domínio público (concessão de uso privativo de bens públicos). Quando preencham determinados requisitos previstos na lei, os contratos de concessão poderão configurar contratos de parceria públicoprivada, ficando sujeitos a um regime especial.

Os contratos administrativos de colaboração estão bem presentes na contratação urbanística e, tipicamente, estão sujeitos a licitação concorrencial. É sobre eles que tem incidido o Direito da União Europeia, em especial as Diretivas da Contratação Pública, dada a atual dimensão do mercado europeu dos contratos públicos. O mercado europeu dos contratos públicos representa cerca de "um quinto do produto interno bruto da União Europeia", o que se traduz em 2.400 mil milhões de euros, valor utilizado pelo setor público administrativo e pelos organismos de direito público para adquirir bens, obras e serviços a empresas privadas. ${ }^{17}$

Mas o ordenamento jurídico português não consagra apenas os contratos administrativos de colaboração. Os contratos administrativos sobre o exercício de poderes públicos (seguem o modelo alemão) também foram acolhidos em Portugal e noutros países do Sul da Europa, como Itália ou Espanha. Tais contratos obedecem a uma lógica completamente distinta. Aqui, não é a Administração que solicita a colaboração do mercado, antes é o mercado que vai procurar a Administração, já que esta tem "na mão" o poder de tomar certas decisões que autorizam e enquadram as atividades (económicas, urbanísticas, ambientais) privadas. Tais decisões administrativas têm um elevado impacto na atividade económica e urbanística: saber em que termos o particular pode (ou não pode)

17 Cfr. European Union (2014, p. 5). Valores que fazem da União Europeia o maior mercado de contratos públicos do mundo, em termos monetários absolutos. No caso de Portugal, a Comissão Europeia estima que no ano de 2011 tenham sido adjudicados 3,67 mil milhões de euros em contratos abrangidos pelas diretivas da contratação pública. 
construir; saber em que termos o particular pode (ou não pode) lotear; saber em que termos o particular pode (ou não pode) explorar uma atividade industrial. Ora, este modelo de contrato administrativo toca o poder de autorização e de licenciamento da Administração, visando modelar a forma como esse poder vai ser exercido no caso concreto. Deste modo, o contrato pode surgir como uma forma de atuação alternativa ao ato e ao regulamento administrativo («contratos substitutivos») ou como um processo que se combina com tais figuras («contratos endoprocedimentais»).

A lei portuguesa consagra, inclusivamente, um princípio geral de paridade ou fungibilidade entre o ato e o contrato administrativo (art. $127 .^{\circ}$ do CPA). Trata-se de matérias que colhem diretamente influência na Parte IV do CPA alemão [ $\$ 54$ a 62 da $V w V f G]$. Enquanto os contratos de matriz francesa consistem num esquema de intercâmbio que visa disciplinar uma relação de colaboração, os contratos de matriz germânica traduzem-se uma forma participada de exercício de um poder público.

No contrato urbanístico estão implicados diferentes tipos de contratos sobre o exercício de poderes públicos: (i) contratos com objeto passível de ato administrativo ou contratos substitutivos de ato administrativo; (ii) contratos endoprocedimentais, pelos quais a Administração se compromete a praticar ou a não praticar ato administrativo com um certo conteúdo; (iii) e contratos sobre o exercício do poder regulamentar (contratos para planeamento). No entanto, este acervo contratual vale apenas no ordenamento jurídico português (e não no brasileiro). Em face do ordenamento brasileiro, podemos qualificar o direito português da contratação administrativa como um sistema híbrido ou misto, situado entre o francês e o alemão. Observa-se, na verdade, uma bipartição fundamental do direito português dos contratos administrativos, ${ }^{18}$ que impõe uma diferenciação de regime jurídico entre os contratos administrativos de colaboração e os contratos administrativos sobre o exercício de poderes públicos.

6. A grande dicotomia na contratação urbanística: contratos para planeamento e contratos de execução de planos urbanísticos

Vimos que a atividade administrativa urbanística apresenta várias conexões com a instituição contratual, quer porque o contrato surge como instrumento jurídico ao serviço da execução de planos (pós-plano), concluído, na terminologia francesa, no âmbito do "urbanismo operativo" sobre a base de um plano já aprovado, com vista a fixar as condições, os termos e os prazos para a sua concretização, quer porque o contrato surge no âmbito do "urbanismo regulamentar" (pré-plano), quer dizer, no decurso do

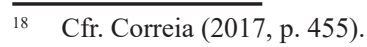


procedimento de planeamento, visando estabelecer os critérios destinados a definir o se, o quando e o modo do exercício do poder de planeamento urbanístico.

Isto significa que se estabelece na contratação urbanística uma grande dicotomia, que permite distinguir claramente os contratos de execução de planos dos contratos para planeamento. Nos primeiros, o contrato assume-se como uma modalidade da ação administrativa que tem em vista disciplinar (scilicet, "acelerar", "garantir" ou "tornar mais eficiente") o modelo de concretização do plano, regulando, detalhadamente, os termos e os prazos para a execução das prescrições urbanísticas. E porque a atividade de gestão urbanística vai implicar várias operações de transformação do território com elevado valor económico, haverá que indagar, se e em que medida, tais contratos estão submetidos às regras da contratação pública, descortinando-se a abundância de jurisprudência europeia em matéria de "mercados públicos da contratação urbanística". ${ }^{19}$

Constituem, no ordenamento jurídico português, "contratos de execução de planos municipais de ordenamento do território", os contratos integrativos dos sistemas de execução dos planos municipais de ordenamento do território (artigos $149 .^{\circ}, 150 .^{\circ} \mathrm{e} 151 .^{\circ}$, do Regime Jurídico dos Instrumentos de Gestão Territorial), os contratos de mediação no controlo prévio das operações urbanísticas [artigos $24 .^{\circ}, \mathrm{n}^{\circ}{ }^{\mathrm{2}}$, b), e 5 , e $25 .^{\circ}, \mathrm{n}^{\circ}{ }^{\circ} 1,3$ e 6 ; artigos $46 .^{\circ}$ e $47 .^{\circ}$ e $55 .^{\circ}$, do Regime Jurídico da Urbanização e Edificação], os programas de ação territorial (artigo 73. ${ }^{\circ}$-A do Regime Jurídico da Reabilitação Urbana [RJRU], aprovado pelo Decreto-Lei n. ${ }^{\circ}$ 307/2009, de 23 de outubro), os contratos no âmbito da expropriação por utilidade pública (artigos 33. ${ }^{\circ}$ a $37 .^{\circ}$, do Código das Expropriações), os contratos de concessão de reabilitação urbana, de reabilitação urbana e de empreitada única (artigos 42. ${ }^{\circ}, 43 .^{\circ}$ e 56. ${ }^{\circ}$ do Regime Jurídico da Reabilitação Urbana) e a contratação referente ao reparcelamento do solo urbano (artigo $165^{\circ},{ }^{\circ}{ }^{\text {os }} 2$ e 3 , do Regime Jurídico dos Instrumentos de Gestão Territorial) e à concretização dos mecanismos de perequação previstos nos planos direta e imediatamente vinculativos dos particulares (artigos 178. ${ }^{\circ}$, n. ${ }^{\text {os }} 5,6$ e 7, e $179 .^{\circ}$, do Regime Jurídico dos Instrumentos de Gestão Territorial).

Já no ordenamento jurídico brasileiro, também se podem reconduzir a uma noção ampla de acordos de execução de planos: as concessões urbanísticas (previstas no direito municipal de certos Estados), as operações urbanas consorciadas (artigos 32. ${ }^{\circ}$

19 Sob ponto de vista funcional, existem certos contratos urbanísticos que podem envolver, no seu âmbito convencional, a realização de obras de urbanização (v.g., arruamentos, redes de saneamento, de conexões de abastecimento de água e eletricidade), a construção de infraestruturas gerais, de instalações desportivas de bairro, de equipamentos sociais ou de centros culturais e recreativos. Quer dizer, por contrato pode a administração municipal adjudicar diretamente ao construtor (ou ao titular de uma licença de construção ou de um projeto de loteamento aprovado) a realização de um leque alargado de obras públicas urbanísticas, o que, segundo a jurisprudência europeia do Tribunal de Justiça, pode, em certas condições, exigir o respeito pelos princípios da concorrência e da igualdade entre os operadores de mercado. 
e segs. do Estatuto da Cidade) e o estudo de impacto de vizinhança (artigos 4. ${ }^{\circ}$, VI, e 36 e segs. da Lei n. ${ }^{\circ}$ 10.257/2001). As concessões urbanísticas foram consagradas nos Municípios de São Paulo (Leis n. ${ }^{\text {os }}$ 14.917/2009 e 14.918/2009) e do Rio de Janeiro (artigo 106 da Lei Complementar n. ${ }^{\circ}$ 111/2011), abrindo caminho a um modelo de gestor urbano (concessionário) semelhante à concessão de urbanização disciplinada na lei portuguesa. ${ }^{20}$

Por sua vez, as operações urbanas consorciadas e o estudo de impacto de vizinhança não correspondem a instrumentos que seguem o modelo geral de contrato administrativo. O estudo de impacto de vizinhança encontra-se, na verdade, mais próximo da figura dos atos administrativos negociados (os encargos correspondem a medidas compensatórias ou de mitigação de impactos verificados). ${ }^{21}$

Por sua vez, os contratos para planeamento envolvem um negócio jurídico que incide sobre o projeto de plano municipal (o plano de urbanização ou o plano de pormenor), através do qual o promotor urbanístico apresenta ao Município um modelo de ocupação territorial. Por conseguinte, o Município recebe, através da Câmara Municipal (a Prefeitura), uma proposta que versa sobre uma determinada conceção de ocupação territorial, ou seja, o contrato apresenta uma solução urbanística para uma determinada área (um projeto detalhado de ocupação dessa área), cuja viabilização depende da elaboração ou alteração de um plano urbanístico municipal. Se a Câmara Municipal aceitar, a pretensão do privado deverá ser incluída numa proposta de plano e, posteriormente, entregue à Assembleia Municipal para aprovação. Neste sentido, o contrato vai influir sobre o conteúdo do plano (as regras do plano), podendo ser objeto do contrato o "desenho", o "regulamento" e as "condicionantes" - cfr. os artigos 79. ${ }^{\circ}$ a $81 .{ }^{\circ}$ do Regime Jurídico dos Instrumentos de Gestão Territorial.

A contratualização do conteúdo do plano urbanístico surge numa fase anterior à aprovação do plano, ou seja, no âmbito do procedimento administrativo de elaboração, alteração ou revisão de um plano de urbanização ou de um plano de pormenor. Contudo, este paradigma de contratação não pode deixar de constituir uma temática problemática. O recurso a este contrato exige uma Administração Pública madura e rigorosa, já que o modelo contratual pode sofrer desvios e adulterações, como a penetração do negócio e do financiamento privado para uma zona que representa a função pública por excelência, a clientelização da Administração, o desvio de poder e a corrupção no setor imobiliário.

A análise da tipologia de contratos urbanísticos e os seus regimes jurídicos encontram-se desenvolvidos na nossa obra, Contratos Urbanísticos, Almedina, Coimbra, 2009, disponível na Biblioteca da Faculdade de Direito da Universidade de São Paulo (Largo de São Francisco). O mesmo se diga da nossa obra, Contrato e poder administrativo,

\footnotetext{
$20 \quad$ Para mais desenvolvimentos, cfr. o Capítulo VI da tese de Guilherme Dias Reisdorfer (2014, p. 155 et seq.).

21 Também sobre este ponto, cfr. Guilherme Dias Reisdorfer (2014, p. 110-153).
} 
Gestlegal, Coimbra, 2017. Trata-se de matéria com elevado teor de detalhe, pelo que se justifica plenamente a remissão para tais monografias.

\section{Síntese comparativa}

Tal como o direito português, o direito brasileiro consagra a colaboração entre o poder público e a iniciativa privada no âmbito urbanístico, sendo uma diretriz geral da política urbana, prevista no artigo 2. ${ }^{\circ}$, inciso III, da Lei n. ${ }^{\circ}$ 10.257/2001 Estatuto da Cidade. Sem prejuízo de diversas semelhanças encontradas (algumas delas caraterísticas comuns ou tendenciais de certas famílias ou sistemas jurídicos), também se descortinam muitas diferenças, fruto de opções históricas, políticas e legislativas. Importa, por isso, proceder à síntese comparativa, lançando algumas conclusões que enunciam as semelhanças e diferenças entre os termos a comparar.

(1) Primeira Conclusão: quando comparado com o direito português, não há no direito positivo brasileiro um tratamento legislativo sistemático sobre a matéria da contratação urbanística. Como observa Fernando Dias Menezes de Almeida (2012, p. 305-306), "não há uma tipificação legal clara desses casos", conquanto seja possível "genericamente supor que a Administração convencione com o particular interessado a adoção de certas condutas como condição da autorização ou da licença”. Em sentido próximo, Guilherme Dias Reisdorfer (2014, p. 158) afirma que “o direito urbanístico brasileiro ainda não apresenta uma realidade urbanística contratual sistemática”.

(2) Segunda Conclusão: quando comparado com a legislação urbanística estruturante em Portugal, é preciso levar em conta que o Estatuto da Cidade é um diploma relativamente jovem, cujas linhas fundamentais assentam num modelo de governação pública unilateral. A própria CF-88 foi a primeira Constituição da República a consagrar um capítulo próprio para a política urbana, estabelecendo vinculações mais exigentes em matéria de ordenamento urbanístico quando comparada com a CRP-76. O próprio Estatuto da Cidade remete para a legislação municipal a disciplina de vários institutos nele previstos (v.g., artigos 5. ${ }^{\circ}, 25^{\circ}, 30 .^{\circ}, 32 .^{\circ}, 35^{\circ}, 36^{\circ}{ }^{\circ}$ e $\left.40 .^{\circ}\right)$.

(3) Terceira Conclusão: quando comparado com a legislação portuguesa, observa-se alguma alergia do Estatuto da Cidade a técnicas contratuais que coloquem excesso de discricionariedade nas mãos do decisor público. ${ }^{22}$ Sem prejuízo da existência de mecanismos negociais e convencionais no direito urbanístico brasileiro, o direito

22 É de reter algumas palavras críticas de Vitor Rhein Schirato (2018), sobre as hesitações na valia dos contratos e da concertação público-privada ["O Brasil é um país que vive em uma constante dúvida. Não sabe se, quando crescer, será um país moderno, aberto, ou se será um país caudilhista tipicamente latinoamericano"]. 
português acolheu e aprofundou o paradigma contratualista na legislação geral de direito administrativo - o Código do Procedimento Administrativo - e na legislação especial de direito do urbanismo - o Regime Jurídico dos Instrumentos de Gestão Territorial e Regime Jurídico da Urbanização e Edificação. Trata-se de realidades assaz distintas.

(4) Quarta Conclusão: observa-se o recurso crescente ao contrato urbanístico em ambos os ordenamentos jurídicos. Após uma fase inicial de parca utilização das figuras contratuais, a última década ficou marcada em Portugal pela utilização crescente dos contratos urbanísticos em três áreas decisivas: (i) no planeamento, com a proliferação de contratos para planeamento, mesmo em Municípios de menor dimensão; (ii) no licenciamento de operações urbanísticas, abundando contratos de urbanização para reforço de infraestruturas gerais dos municípios e para a realização de obras de urbanização; (iii) e no âmbito da reabilitação urbana, com a proliferação de contratos de concessão e alguns contratos de empreitada única. A utilização crescente do contrato refletiu o aumento do investimento privado e o aquecimento do mercado imobiliário.

(5) Quinta Conclusão: a contratação urbanística deve ser submetida a rigoroso escrutínio pelos órgãos fiscalizadores e pela sociedade civil. Existem riscos associados a certo tipo de negociações. Vivemos num mundo urbano com uma forte pressão sobre as infraestruturas, os serviços públicos e o meio ambiente da cidade. Existem muitos casos de sucesso, em que a intervenção do contrato permitiu a concretização de projetos urbanísticos que cumprem patamares de qualidade, apresentam soluções inovatórias, observam as regras ambientais e correspondem a um padrão de boa administração. Contudo, a história da «governação por contrato» não é feita só de sucessos: também houve insucessos e devemos encará-los com realismo. E o que a experiência nos diz é que deve ser recusada a utilização do contrato em certos cenários: (i) quando o contrato projeta uma alteração ao plano que somente tem em vista "legalizar" operações urbanísticas que são ilegais à luz do plano em vigor; (ii) quando o contrato constitui um expediente de financiamento para o município, financiamento que retorna à esfera privada sob outra forma de compensação, quase sempre de modo pouco transparente (lógica do intercâmbio ou da "liquidação total dos poderes públicos"). A essas duas tendências soma-se uma outra que teve grande impacto em Espanha. A existência de grupos de pressão interessados na expansão do espaço urbano fez dos convenios urbanísticos de planeamiento um instrumento ao serviço da especulação imobiliária, por via da alteração da qualificação do solo, gerando mais-valias desprovidas de justificação. Esta experiência negativa, que ocorreu na primeira década do século XXI, obrigou à alteração de regras em Espanha, visando pôr termo a casos de desvio de poder, no domínio administrativo, e de crimes de corrupção, no foro penal.

Isso não significou lançar sobre este tipo de contratos o anátema da rotura com princípios e valores fundamentais do direito administrativo ou considerar 
que o interesse público sai necessária e irremediavelmente comprometido com a celebração de contratos desta natureza. Pelo contrário, quando a Administração goza de discricionariedade na aplicação da lei, a violação de princípios jurídicos fundamentais, também, se pode processar por via unilateral, através da prática de atos administrativos. Por conseguinte, o que a experiência espanhola vem demonstrar é que uma Administração - seja por contrato ou por ato administrativo - deve sempre cumprir com diligência o dever de acautelar a realização do interesse público e não se deixar capturar pelo parceiro privado, tanto nas negociações como na execução dos compromissos assumidos.

Coimbra, agosto de 2020.

\section{Referências}

ALMEIDA, Fernando Dias Menezes de. Contrato administrativo. São Paulo: Quartier Latin, 2012. p. 12 et seq.

AROZAMENA SIERRA, Jerónimo. Algunas consideraciones sobre la institución contractual y el Urbanismo: los llamados convenios urbanísticos. Revista de Derecho Urbanístico y Medio Ambiente, Madrid, ano 30, n. 146, p. 11-26, 1996.

ARREDONDO GUTIÉRREZ, José Manuel. Los convenios urbanisticos y su régimen jurídico. Granada: Comares, 2003. p. 1-80.

BARBOZA, Olavo Sachetim. Contratos urbanísticos no direito português: a análise da aplicação do princípio da concorrência consagrado na Diretiva da União Europeia 2014/24/EU aos contratos de execução e aos contratos para planeamento. Revista Digital de Direito Administrativo, Ribeirão Preto, v. 5, n. 2, p. 364-391, 2018.

BARLOY, François. Quelques observations sur la présence du contrat en droit de l'urbanisme. In: CLAMOUR, Guylain; Ubaud-Bergeron, Marion. (coord.). Contrats publics: mélanges en l'honneur du professeur Michel Guibal, Montpellier: Université Montpellier, 2006. v. 2. p. 47-62.

BASSOLS COMA, Martín. Contratos urbanísticos. Revista de Derecho Urbanístico y Medio Ambiente, Madrid, n. 275, ano. 46, p. 216-217, jul./ago. 2012.

BATTIS, Ulrich; KRAUTZBERGER, Michael; LÖHR, Rolf-Peter (Hrsg.). Baugesetzbuch. München: C. H. Beck, 2007.

BICK, Ulrike. Städtebauliche Verträge. Deutsches Verwaltungsblatt (DVB1), Köln, p. 154-161, 2001.

BIRK, Hans-Jörg. Städtebauliche Verträge: Inhalte und Leistungsstörungen. Stuttgart: Boorberg, 2002. p. 41-78. 
BOBBIO, Luigi. Produzione di politiche a mezzo di contratti nella pubblica amministrazione italiana. Stato e Mercato, Bologna, n. 58, p. 111-141, aprile 2000.

BOBBIO, Luigi; CRIVELLI, Ruggero. La contractualisation des politiques publiques. PFISTER, Barbara; CRIVELLI, Ruggero; REY, Michel (dir.). Finances et territoires: leur place dans la prise de décision publique. Lausanne: Presses Polytechniques et Universitaires Romandes, 1999.

BORELLA, Alberto. L'urbanistica contrattata dopo la legge 241 del 1990. Rivista Giuridica di Urbanistica, Rimini, n. 4, p. 419-447, 1998.

BORRI, Dino. Urbanistica contrattata. In: BARBIERA, Lelio. Urbanistica contrattata e tutela dell'ambiente. Bari: Cacucci, 2007. p. 17-21.

BROHM, Winfried. Städtebauliche Verträge zwischen Privat- und Öffentlichem Recht: Zugleich ein Beitrag zu den „Einheimischen-Modellen“. JuristenZeitung, Tübingen, v. 55, n. 7, p. 321-332, 2000.

BÜCHNER, Hans; SCHLOTTERBECK, Karlheinz. Baurecht: Städtebaurecht einschließlich örtlicher Bauvorschriften. Stuttgart: W. Kohlhammer Verlag, 2008. Band 1. p. 301-316.

BUSTILLO BOLADO, Roberto O.; CUERNO LLATA, José Ramón. Los convenios urbanísticos entre las administraciones locales y los particulares. Pamplona: Aranzadi, 2001. p. 25-89.

CANDIAN, Albina; GAMBARO, Antonio. Le convenzioni urbanistiche. Milano: Giufrrè, 1992. p. 3-64.

CANO MURCIA, Antonio. Teoría y práctica del convenio urbanistico. Pamplona: Aranzadi, 2006, p. 28-60.

CENTOFANTI, Nicola. Le convenzioni urbanistiche ed edilizie. Milano: Giuffrè, 2007, p. 3-27.

CHEVALLIER, Jean-Jacques. Bilan de recherche sur la participation dans 1'administration française. In: . La participation dans l'administration française. Paris: PUF, 1975. p. 5-57. p. 11-12.

CIVITARESE MATTEUCCI, Stefano. Contributo allo studio del principio contrattuale nell'attività amministrativa. Torino: Giappichelli, 1997.

CIVITARESE MATTEUCCI, Stefano. Sul fondamento giuridico degli accordi in materia di fissazione delle prescrizione urbanistiche. In: FERRARI, E.; PUGLIESE, F. (ed.). Presente e futuro della pianificazione urbanistica. Milano: Giuffrè, 1999. p. 132-141.

CORREIA, Fernando Alves. Manual de direito do urbanismo. Coimbra: Almedina, 2008. v. 1. p. 469-483.

CORREIA, Jorge André de Carvalho Barreira Alves. A contratação urbanística em Portugal à luz do Código dos Contratos Públicos e do Direito da União Europeia. Direito Regional e Local, Braga, n. 19, p. 27-41, 2012. 
CORREIA, Jorge André de Carvalho Barreira Alves. Contrato e licenciamento de operações urbanísticas no RJUE. In: CARVALHO, Ana Celeste; DAVID, Sofia (org.). Direito do urbanismo, 2014-2017: jurisdição administrativa e fiscal. Lisboa: Centro de Estudos Judiciários, jul. 2018. p. 91-112. (Coleção Formação Contínua).

CORREIA, Jorge André de Carvalho Barreira Alves. Contrato e poder administrativo: o problema do contrato sobre o exercício de poderes públicos. Coimbra: Gestlegal, 2017. p. 555 et seq.

CORREIA, Jorge André de Carvalho Barreira Alves. Contratos urbanisticos: concertação, contratação e neocontratualismo no direito do urbanismo. Coimbra: Almedina, set. 2009.

CORREIA, Jorge André de Carvalho Barreira Alves. Direito público luso e brasileiro: um exercício de direito constitucional comparado. 2. ed. Coimbra: Gestlegal, 2019. p. 15 et seq.

CUGURRA, Giorgio. Accordi e pianificazione territoriale e ambientale. Rivista Giuridica di Urbanistica, Rimini, p. 144-155, 2005.

EUROPEAN UNION. Council of the European Union. Commission staff working document: annual public procurement implementation review, 2013. SWD(2014) 262 final. Brussels, 1 ago. 2014. Disponível em: https://data.consilium.europa.eu/doc/document/ST\%2012642\%202014\%20 INIT/EN/pdf.

FREEMAN, Jody. The contracting State. Florida State University Law Review, Tallahassee, v. 28, n. 1,2000 .

FRIER, Pierre-Laurent. Contrats et urbanisme réglementaire: les obstacles juridiques. Revue Droit Administratif, Paris, n. 3, Mars 2005. p. 13-15.

GJIDARA, Marc. Les procédés contractuels entre partenaires publics: les contrats entre l'état et les collectivités territoriales. Zbornik radova Pravnog fakulteta u Splitu, Splitu, v. 48 n. 2, p. 289-320, 2011. Disponível em: https://hrcak.srce.hr/file/301098.

GONÇALVES, Pedro Costa. Direito dos contratos públicos. Coimbra: Almedina, 2015. p. 427 et seq.

GURLIT, Elke. Verwaltungsrechtlicher Vertrag und andere verwaltungsrechtliche Sonderverbindungen. In: ERICHSEN, Hans-Uwe; EHLERS, Dirk (Hrsg.). Allgemeines Verwaltungsrecht, Berlin, 2010. p. 756-831.

GURLIT, Elke. Verwaltungsvertrag und Gesetz: eine vergleichende Untersuchung zum Verhältnis von vertraglicher Bindung und staatlicher Normsetzungsautorität. Tübingen: Mohr Siebeck, 2000. p. 36-42. (Jus Publicum 63).

HUERGO LORA, Alejandro. Los convenios urbanísticos. Madrid: Editorial Cívitas, 1998. p. 27-32. JACQUOT, Henri; PRIET, François. Droit de l'urbanisme. Paris: Dalloz, 2006. p. 451-455. 
JARASS, Hans Dieter (Hs.). Städtebauliche Verträge und Vergaberecht: Symposium des Zentralinstituts für Raumplanung an der Universität Münster am 24. Juni 2009. Berlin: Lexxion, 2010 .

KOCH, Eva. Städtebauliche Instrumente bei der Konversion von Militärarealen. Berlin: Lexxion Verlagsgesellschaft, 2012.

KRAUTZBERGER, Michael. Städtebauliche Verträge in der praktischen Bewährung. Umwelt- und Planungsrecht, [s. l.], Helf 11/12, p. 407-414, 2007.

KRAUTZBERGER, Michael. Zum Stellenwert von städtebaulichen Verträgen im heutigen Städtebau, Umwelt- und Planungsrecht, [s. l.], Helf 1, 2006. p. 1-4.

LEITÃO, Alexandra. A contratualização no direito do urbanismo. Revista Jurídica do Urbanismo e do Ambiente, Coimbra, n. 25-26, p. 9-32, jan./dez. 2006.

LENZ, Christofer; WÜRTENBERGER, Thomas. BauGB-Verträge: Leitfaden für Gemeinden und Investoren. Stuttgart: Boorberg, 2011.

MAGRI, Marco. Gli accordi con i privati nella formazione dei piani urbanistici strutturali. Rivista Giuridica di Urbanistica, Rimini, n. 4, p. 539-587, 2004.

MARQUES NETO, Floriano Peixoto de Azevedo. O direito administrativo no sistema de base romanística e de common law. Revista de Direito Administrativo, Rio de Janeiro, v. 268, p. 55-81, jan./abr. 2015. p. 74

MAZZA, Maria Grazia. Il trasferimento della capacità edificatoria: disciplina, effetti ed opportunità pubbliche e private. Matelica: Halley, 2005.

MUNDIM, Gabriel Abdallah. A concessão urbanística. 2014. Dissertação (Mestrado em Direito) Faculdade de Direito, Universidade de São Paulo, São Paulo, 2014.

NIGRO, Mario. Convenzioni urbanistiche e tutela nei rapporti tra privati. Problemi Generali. In: COSTANTINO, Michele (ed.). Convenzioni urbanistiche e tutela nei rapporti tra privati. Milano: Giuffrè, 1995. p. 33-66.

OCHOA GÓMEZ, María Pilar. Los convenios urbanísticos: límites a la figura redentora del urbanismo. Madrid: La Ley, 2006. p. 15-55.

OLBERTZ, Karlin. A operação urbana consorciada. Belo Horizonte: Fórum, 2011.

OLIVEIRA, Fernanda Paula; LOPES, Dulce. O papel dos privados no planeamento: que formas de intervenção? Revista Jurídica do Urbanismo e Ambiente, Coimbra, ano 10, n. 20, p. 43-79, dez. 2003.

OTERO, Paulo. Legalidade e administração pública. Coimbra: Almedina, 2003. p. 838. 
PARENTE, Ferdinando. Programmazione negoziata attuativa di dettaglio e trasformazione del territorio. In: BARBIERA, Lelio. Urbanistica contrattata e tutela dell'ambiente. Bari: Cacucci, 2007. p. 181-196.

PORTIER, Nicolas. Un nouveau mode de relations entre l'Etat et ses partenaires: l'exemple de l'aménagement du territoire. Actualité Juridique Droit Administratif - AJDA, Paris, n. 19, p. 986989, 2003.

REISDORFER, Guilherme Fredherico Dias. Direito urbanístico contratual: dos atos negociais aos contratos de gestão urbana. Rio de Janeiro: Lumen Juris, 2014.

RICCIO, Thiago Quintão. Operação urbana consorciada: contratualização na execução da política urbana concertada. 2015. Dissertação (Mestrado em Direito) - Faculdade de Direito, Universidade Federal de Minas Gerais, Belo Horizonte, 2015.

RICHER, Laurent. La contractualisation comme technique de gestion des affaires publiques. Actualité Juridique Droit Administratif, Paris, n. 19, p. 973-975, 2003. p. 973.

SANT'ANNA, Mariana Senna. Estudo de impacto de vizinhança: instrumento de garantia da qualidade de vida dos cidadãos urbanos. Belo Horizonte: Fórum, 2007.

SCHIRATO, Renata. A interação público-privada na realização do direito urbanístico. In: MEDAUAR, Odete; SCHIRATO, Vitor Rhein; MIGUEL, Luiz Felipe Hadlich; GREGO-SANTOS, Bruno (coord.). Direito urbanístico: estudos fundamentais. Belo Horizonte: Fórum, 2019. p. 249272 .

SCHIRATO, Vitor Rhein. Vivemos dias turvos em nosso direito administrativo. Consultor Jurídico, São Paulo, abr. 2018. Disponível em: https://www.conjur.com.br/2018-abr-01/vitor-schiratovivemos-dias-turvos-nosso-direito-administrativo.

SCHLETTE, Volker. Die Verwaltung als Vertragspartner: Empirie und Dogmatik verwaltungsrechtlicher Vereinbarungen zwischen Behörde und Bürger. Tübingen: Mohr Siebeck, 2000. (Jus Publicum 51).

SCHMIDT-ASSMANN, Eberhard; KREBS, Walter. Rechtsfragen städtebaulicher Verträge: Vertragstypen und Vertragsrechtslehren. Bonn-Bad Godesberg: Bundesminister für Raumordnung, Bauwesen u. Städtebau, 1988. (Schriftenreihe "Forschung" des Bundesministers für Raumordnung, Bauwesen und Städtebau, Heft 460).

SENDÍN GARCÍA, Miguel Ángel. Régimen jurídico de los convenios urbanísticos: adaptado a la nueva ley del suelo (Ley 8/2007, de 28 de mayo, de suelo) y la nueva ley de contratos del sector público (Ley 30/2007, de 30 de octubre, de contratos del sector público). Granada: Comares, 2008. p. 11-39.

SPARWASSER, Reinhard; ENGEL, Rüdiger; VOßKUHLE, Andreas. Umweltrecht: Grundzüge des öffentlichen Umweltschutzrechts. Heidelberg: C. F. Müller, 2003. 
TANQUEREL, Thierry; MORAND-DEVILLER, Jacqueline; CORREIA, Fernando Alves (dir.). La contractualisation dans le droit de l'urbanisme. Paris: Gridauh, 2014. (Les Cahiers du GRIDAUH, n. 25).

URBANI, Paolo. Urbanistica consensuale: la disciplina degli usi del territorio tra liberalizzazione, programmazione negoziata e tutele differenziate. Torino: Bollati Boringhieri, 2000.

VERKUIL, Paul R. Outsourcing sovereignty: why privatization of government functions threatens democracy and what we can do about it. Cambridge: Cambridge University Press, 2007.

VICENTE DÍAZ, Violeta. El procedimiento concurrencial como nuevo modelo de desarrollo de la actividad de gestión urbanistica: los programas de actuación urbanizadora en la legislación urbanística de Castilla-La Mancha. Pamplona: Aranzadi, 2003.

VINCENT-JONES, Peter. The new public contracting: regulation, responsiveness, relationality. Oxford: Oxford University Press, 2006. 